Editor's Note: This is the second of what I hope will be a regular feature. Paul Munroe wrote about Microscopy in Australia in the Nov./Dec. issue. Luc Harmsen shares his views on microscopy in Southern Africa in this issue. We would like to encourage future contributions from correspondents elsewhere, reporting on the state of microscopy in their part of the world! Contact me via the addresses on page 6 .

\section{The Year That Was! Microscopy in Southern Africa}

\author{
Luc Harmsen \\ Anaspec, South Africa \\ luc@anaspec.co.za
}

If we look back at the year 2003 it becomes quite clear that the South African microscopy year was quite unique. ... Of course, I can't speak for all the companies and laboratories in the country, but from my personal view it was definitely interesting.

FEI definitely had a great year in that they managed to sell 5 systems. Then LEO added to that another 3 , and we have heard that there is also a Cameca probe being bought. This may not sound like a lot, but if you take into consideration that in the last few years an average of 4-5 EM columns per year would register as a banner year. Given that we have seen our currency improve over the past 2 years, it does imply that buying imported equipment is getting cheaper. However as this effect has also negatively affected exports, we can't say that we have become richer, and so could afford more systems.

As far as who sells what and who has technicians-that has remained pretty constant, for a change. With Wirsam now also outsourcing technical support to Electron Beam Technical Services, I am sure South Africa is very unique in that only one agent, selling EM, still keeps it's own in-house technical support engineer for EM. The rest all out source their technical support. In this way, I think, we have a more solid support structure as outsourcing implies that technical support is being paid for, not just accepted as a necessary evil in a sales orientated company! This has also meant that we have seen more spent on factory training and better technical support for the clients.

Yes, you can argue that I must say this in light of Anaspec being a support company, as it markets Anaspec, but remember that I have travelled quite a bit this year, doing technical support. The main reason for the lack of support in these countries has always come down to the fact that the service engineers are not paid well and so move on.

Then if we look at who bought the systems in South Africa, we see that most of them went to industry. In particular the mining industry, who have had a good time when our currency was poor with their exports. But now are experiencing a bad time of it as it strengthens again. This has also meant that we now have a very large basis of microscopy within the mineralogical applications. Where the rest of the world would be investing in semiconductor or biological fields, true to our economy, we find that our strong mining economy is also benefiting our microscopy world.
We also saw a TEM sold again. Unusual in that this doesn't happen often, as they are normally only bought by universities and, like in all other countries at the moment, universities don't have great funding.

One even more infrequent event was that a microscope at a university has been upgraded rather than replaced. The University of Potchefstroom had a very nice FEI XL SEM, which they upgraded to the latest Quanta ESEM, just 8 years later. This meant that they actually got money back for the old system from FEI not from the agent and so the "old" system is not staying here but going back to FEI. Most Universities normally don't have that sort of client base or funding to enable this sort of transaction.

From Anaspec's side, we have also had a first for the South African market in that we started a Technical Support Branch in Australia. They may beat us at everything, but it's nice to know that we can still work with them on the microscopy side. In this way, once again, I can strengthen the argument to outsource technical support. It is so strong in SA that we can actually export this "product." Through this new development we were then able to establish contact between our local microscopy association and Australia's association. MSSA (Microscopy Society of Southern Africa) invited a representative from the Australian Nano company to our conference to strengthen ties between our two countries. We are hoping that this will result in more co-operation on research matters and will also expose us to new equipment that Australia has and South Africa can't afford as yet.

In late November we also had the establishment of the first SABS and CSIR backed committee, looking into standards for microscopy and laboratory practices within South Africa. This committee has ties directly with the international standards organization (ISO) and can also give input on ISO standards in microscopy and particularly in microanalysis.

We also saw another microscopy laboratory going into neighboring countries. Well, into Botswana to be more specific. The University has had a TEM, SEM, confocal, and various light microscopes for a year or two now. This has also been reflected at our MSSA Conference where we had a number of papers being presented from the students of the University of Botswana. The Botswana Geological Survey has also taken a new SEM for mineralogical analysis purposes. Again showing how South African Microscopy follows it's major business sector in that we are now getting far more exposure in mining and mining related industries.

We have not seen any new and exciting equipment installed like a SIMS, FEG-TEM, or an X-Beam.

MSSA also had a change. Following the success of ICEM 15 in 2002, the society finds itself with a bit more cash than it had in the past. This means we can start being more active in promoting microscopy in the region of Southern Africa. It promises to be a good year ahead for MSSA with a lot of work to do. Suggestions of microscopes to schools, marketing material such as CD's and videos, and more international exposure for members is all in the ideas basket for MSSA.

So, again I stress this is my view on the year that was, I think South African microscopy had a good year in 2003, and with the strengthening of the Rand, we can only look forward to an even better year next year. 